\title{
A Sustainability Assessment on Sino-Foreign Cooperative Design Major and an Appraisal of the Innovative Application of MOOCS
}

\author{
Tiejun Zhu, ${ }^{\mathrm{a}, *}$, Michael Berry ${ }^{\mathrm{b}}$ \\ ${ }^{a}$ Art School, Anhui Polytechnic University, Wuhu, 241000, China \\ ${ }^{b}$ English Language Centre, University of Liverpool, Liverpool, 241000, L69 7ZX, United Kingdom
}

\begin{abstract}
In the recent advocated reform of education and teaching by China's education ministry, the MOOCS teaching concept and mode is widely used in higher education teaching systems. This paper focuses on the Sino-foreign cooperative design major and examines its unique curriculum, teaching system, talent cultivation and other characteristics, through the selection of different levels and different types of representative colleges and universities and Sino-foreign cooperative design majors. Utilizing varieties of methods including questionnaire investigation, face-to-face interview and discussion, statistical analysis, long-term tracking research and so on, this paper aims to research, analyze, demonstrate and reveal the effects of introducing MOOCS mechanisms in education. The teaching of the Sinoforeign cooperative design major, especially points to embodied advantages and disadvantages to show its reliability, performability and existing risks. The paper puts forward suggestions for improvement; countermeasures and sustainability assessments so as to further improve and optimize MOOCS, deepen application and better promote the reform of education and teaching in the corresponding fields in China.
\end{abstract}

Keywords: MOOCs; innovative application; sustainability assessment; sino-foreign cooperative design major; empirical research; supporting analysis; availability optimization

(Submitted on October 20, 2017; Revised on December 17, 2017; Accepted on December 24, 2017)

(C) 2018 Totem Publisher, Inc. All rights reserved.

\section{Introduction}

"MOOCs are a fairly new phenomenon that has taken the world by storm." [4] "The recent introduction of MOOCs has a profound impact in the world." [16] Under the initiative of China's education ministry, schools at all levels in China, especially colleges and universities, are all following the educational reform to develop, apply and systematize the teaching mode of MOOCs. Sino-foreign cooperative majors, developing at top speed, are amongst the priorities the public calls for reform. Indeed, Sino-foreign cooperative major, as a rising power and a trend in the domain of higher education, has been gaining great momentum in an unpredictable way in China ever since the 1990s. As a result, the integration of the emerging teaching model of MOOC and the teaching system of Sino-foreign cooperative design major (hereinafter referred to as SFCDM) will both follow the educational reform and take the lead in this domain.

Due to historical factors, China, as a late starter in the education of design with a low base, lacks a long history of modern design. Meanwhile, Europe and the United States both boast a profound historical culture as well as an advanced educational concept and system of design. In face of these disparities, a lot of colleges and universities in China have a rather strong interest in cooperating with foreign counterparts in terms of design majors. With that being the case, SFCDM is now flourishing across China. According to the statistics, 63 SFCDMs covering 21 provinces, cities and autonomous regions, have been approved by the education ministry of China by the end of August 2016. Also, another 49 SFCDMs yet to be approved have been filed by the local governments. They cover 19 provinces and as many as 112 cities and 
autonomous regions, as is depicted in Table 1 . By now, $52 \%$ of all these majors have introduced MOOCs, and even $15 \%$ of colleges and universities have established their own MOOC platforms about design.

Table 1. The number and distribution of SFCDM in China (by the end of August 2016)

\begin{tabular}{|c|c|c|c|c|c|}
\hline \multicolumn{2}{|c|}{$\begin{array}{c}\text { Division by region of the foreign } \\
\text { cooperative partner territory }\end{array}$} & \multicolumn{2}{c|}{$\begin{array}{c}\text { Division by region of Chinese universities } \\
\text { and colleges }\end{array}$} & \multicolumn{2}{|c|}{ Division by education level } \\
\hline Europe & 41 & Eastern China & 76 & Chinese-foreign Cooperative Organization & 12 \\
\hline North America & 23 & Central China & 18 & Master education & 3 \\
\hline Oceania & 17 & Western China & 7 & Undergraduate education & 56 \\
\hline Asia & 31 & Northeast China & 11 & Junior college education & 41 \\
\hline
\end{tabular}

\section{Background}

In order to make the research results more typical and universal, the researchers have listed seven targeted Chinese colleges and universities with different levels and SFCDM held by assorted regions and nations. By doing so, they have also made some deep investigations and track records on the application of MOOCs in various ways like conducting interviews, questionnaires, statistics, contrasts and assessments. Selected samples are shown in Table 2.

Table 2. Selected samples and time length of MOOCs application (by the end of August 2016)

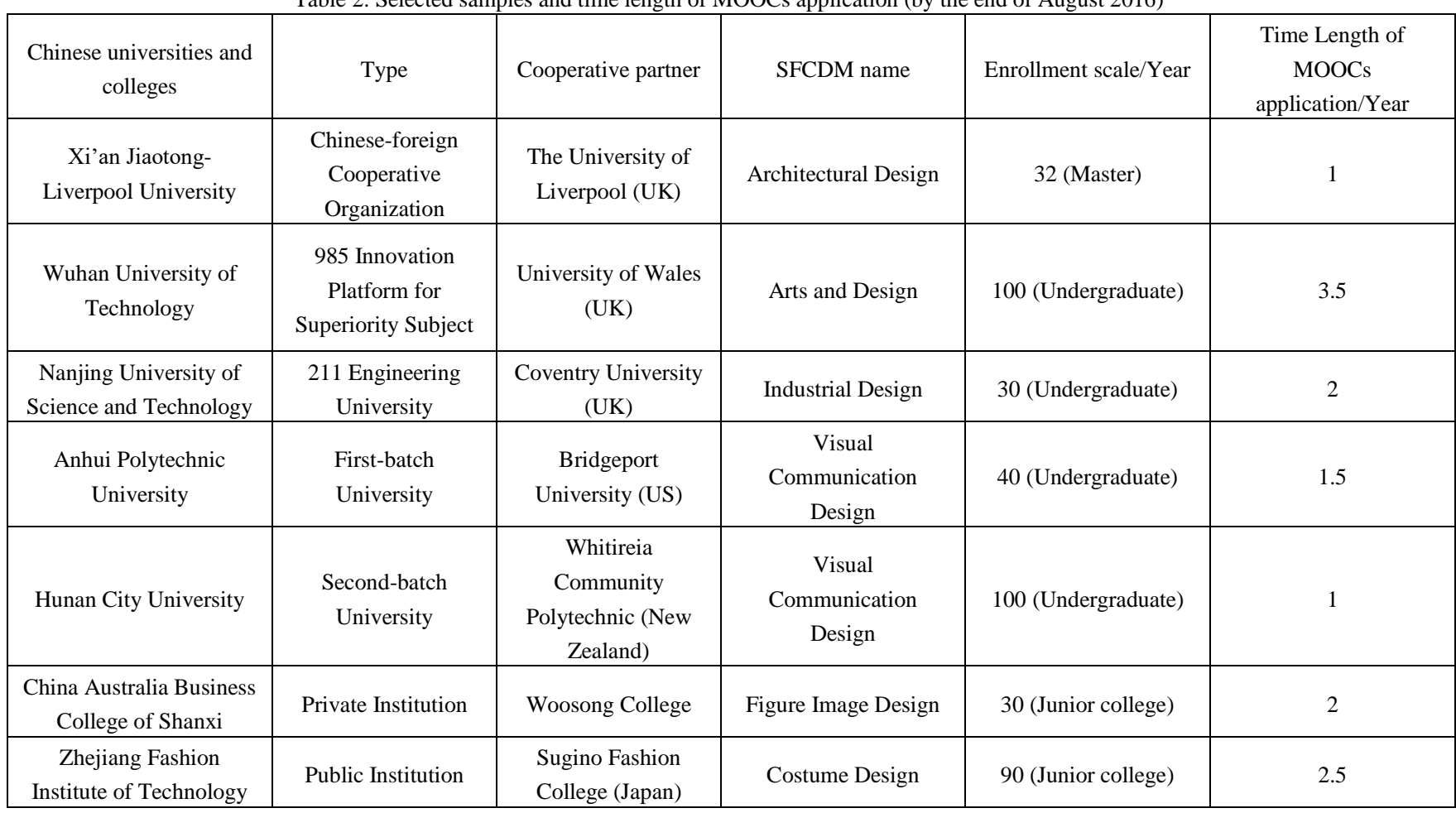

The main contents of this questionnaire (15 students are selected from the first and second grades of SFCDM in each sample university where at least two MOOCs have been completed, and a total of 210 students from 7 colleges and universities) are as follows: the questionnaire included 44 questions, of which 1 to 7 focused on basic information about the students; 8 to 13 inquired about students' similar extent to MOOCs before they experienced the MOOC teaching model; 14 to 22 inquired about students' various MOOC learning states and related reasons such as motives for MOOCs learning, the principles of course selection, the feelings, problems and causes in the learning process, the reasons for dropping out of MOOCs, etc.; 23 to 30 investigated students' views on advantages of MOOCs and their achievements after learning in MOOCs such as acquired abilities and enhanced qualities; 31 to 39 were based on students' self-assessments to collect all kinds of problems they had encountered during the MOOCs learning period and their suggestions; 40 to 44 mainly surveyed students' satisfaction degree about MOOCs through comparison with other teaching methods and teaching resources after the application of MOOCs introduction mechanism in SFCDMs' teaching. As for the results of the questionnaire, the paper will give specific analysis in the following content. 
The study on the process of data collection and the procedures of analysis are extremely strict and precise. Firstly, the data is collected through an overall orientation, the interjection at important points and online follow-up. For instance, both real-time and effective data is collected by conducting interviews or questionnaires in some important points and through a close track with the help of network platforms, social media tools, or other APPs. Secondly, scientific analysis of the aggregated data is adopted. For one thing, comparison, trend analysis, and modeling are used to make quantitative analysis; for another, prediction, induction, deduction, and discussion are exploited by the research group as well. For example, when figuring out the rules of students' course selection, the researchers have not only conducted questionnaires, but also discussed and summarized the results. They have also listed every possible rule with prediction beforehand and then made a comparison to the real research result for deeper specific causes. By doing so, the learning state and thoughts of students are precisely determined. Thirdly, timely adjustment, assessment and feedback are applied. If variances that do not coincide with real cases are detected while collecting and analyzing data, adjustments are made in no time. When it comes to the research results, the mechanism of assessment and feedback is adopted. The research group has made a self-assessment and a primary evaluation on data source object. Meanwhile, a formal evaluation from the unit where data was collected and a reevaluation from application department after submission are also made. All of the above are conducted only to ensure that the research data as well as the results are scientific, effective, and practical.

“Typical utilization of MOOCs range from executive education to developer training, compliance training etc," [14] but "there is very limited research carried out on MOOCs' utilization." [3] This paper aims to analyze the strengths and weaknesses MOOCs manifest in the application of the teaching system of SFCDM in an all-dimensional way. While improving the teaching systems of some majors in which MOOCs have already been carried out, the paper will also help SFCDM students draw on advantages and avoid disadvantages. In conclusion, both the utility of MOOCs and the learning efficiency of students can be elevated. The research results can also be a reference to the upcoming MOOCs teaching reform or any colleges with an intention of introducing MOOCs.

\section{Innovative application effectiveness and reliability analysis}

\subsection{An Excellent Tool to Improve English Effectively}

The requirements on foreign language proficiency vary significantly between SFCDM students and those from regular classes sharing the same major. For SFCDM students, strong English skill is of great essence in that they will later study abroad, and even in some non-English speaking countries, TOEFL and IELTS results are also widely recognized. In this case, it is crucial for these students to elevate their English through online courses. "In China, the overall English ability of students studying fashion art and design is relatively low. MOOC provides a large number of courses delivered in English, through which students can enhance their language proficiency". [11] Currently, courses for SFCDM available in MOOCs weigh more on English courses when it comes to course selection and recommendation and also encourage students to attend English courses provided by the three MOOCs giants like Coursera, Udacity and edX. "According to the statistics, only $12 \%$ of the total courses on Coursera and Udemy are not delivered in English." [15] Thanks to the massive number of diverse online courses, students are supposed to choose courses based on their own tastes so that they will be less likely to feel bored while studying English. Additionally, the majority of courses in MOOCs add some interactive sessions during class such as quizzes, feedback on learning, and peer assessments. This creates excellent opportunities and scenarios for SFCDM students to practice and improve their English.

\subsection{A Helpful Supplement to Assess Personal Interests and Expand Knowledge}

"MOOCs provide a rather strong teaching framework and personalized way of learning." [13] Courses in MOOCs are compact and rich in content so that students can choose courses respectively according to their interests. This is helpful for students' self-study and self-assessment on the ability and reason to study, which can eliminate their reluctance towards learning and makes them study in a more active way. Additionally, since the talents of design need to be equipped with a wide range of knowledge to build connections with various fields, the introduction of MOOCs will not only provide a sea of extensive knowledge for users to pick up, but also represent a platform where design students can gain new ideas and inspiration in the following days. Figure 1 shows the learning process of "Thinking, Fast and Slow", a MOOC course selected by students from SFCDM in AHPU, with an aim to broaden their minds on design. This MOOC is introduced from the MOOC platform of University of Michigan, one of the partner universities of AHPU. 


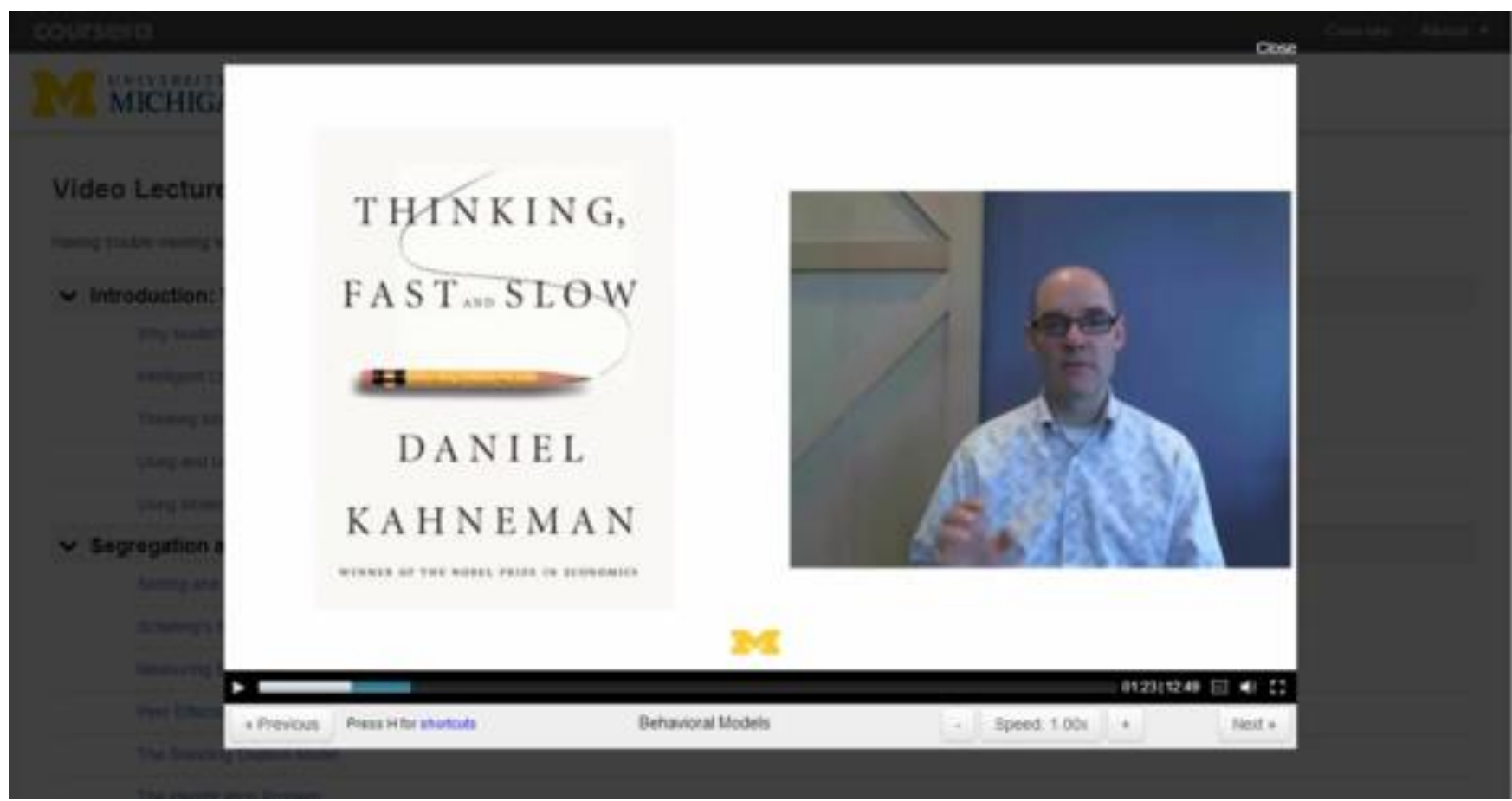

Figure 1. Design thinking development category of MOOC (Thinking, Fast and slow) learning interface: selected by a SFCDM student of Anhui Polytechnic University according to his learning interest

\subsection{A Platform to Acquire the Ability to Design and Develop Innovative Consciousness}

"Sino-foreign cooperative projects aim at cultivating international talents, to whom innovation is the most essential factor." [10] As a matter of fact, the majority of courses in MOOCs are designed by many well-learned and experienced teachers from prestigious universities across the world. Many courses, the design courses in particular, blend the unique thinking, creative ability, and innovative ideas from these masters of design. This means that students can not only develop a close tie with teachers who can explain complicated ideas to students in simple and lucid ways, but also experience and understand the splendid wisdom and innovative vision from them.

\subsection{A Viewfinder to Capture the Cutting-edge Fashion and Design}

Sino-foreign cooperative projects require outstanding international education resources due to the fact that design projects are bound to be brought in line with international design and fashion trends. However, this requirement is evidently not that simple to fulfill for the majority of colleges and universities in China. They need to spend a great deal building a window leading out to international fashion and design, but students can hardly afford such higher costs on learning. The introduction of MOOCs is an excellent remedy. Courses in MOOCs, focusing on a number of new and cutting-edge designs, are equivalent to the viewfinder of a camera, through which sophisticated pictures that reflect the latest trend and the new international fashion designs are captured from cyberspace to present before students. In a questionnaire aimed at SFCDM students under a random sampling survey (a total of 210 students were selected from the seven sample universities, with 30 students each), $29 \%$ of them, when asked the reason why they are keen on MOOCs, chose the option in the questionnaire that stated that "MOOCs can provide up-to-date information about fashionable design and make it possible to gain access to design trends."

\subsection{A Platform Free from the Barriers Caused by Time and Space}

MOOC's online resources successfully remove the barriers coming along with time and space, and this is its biggest advantage. "Any individual, wherever he or she lives on earth, can be enrolled in MOOCs without any strict official permission as long as the Internet is available." [1] MOOCs convey a sense of freedom and intimacy for its learners especially for those growing up in the Internet age. In MOOCs, students can be involved in all the high-quality refined courses across the world, and can replay the videos of every course whenever running into difficulties. In this sense, selflearners are completely free to make their own schedules in terms of studying time and contents. MOOCs, different from traditional teaching that is confined to a certain time and space, can fully mobilize students' enthusiasm and participation in 
learning. "As MOOC gains its own popularity, a new virtual commercial education community that focuses on courses and colleges across time and space is gradually coming into existence." [8]

\subsection{A Supplement to Make Up the Shortage of Teachers and Funds}

Due to the special training for international talents that is required by SFCDM, more excellent teachers, high-quality teaching facilities, smaller-sized classes, and more teaching practices are badly needed, especially experienced design masters. Even though colleges and universities can invite highly-paid designers to give lectures on specific topics, it cannot ensure when these lectures will be delivered. In this sense, as is shown in Table 3, the educational costs and efforts SFCDM needs are much higher than any other regular classes even in the same major. Overall, education resources in China are unequally distributed, barely able to meet the needs of multiples SFCDMs. Even worse, some colleges and universities can only make ends meet. (College and university tuition fees are regulated by local financial departments. Due to the low charges in some provinces, some colleges and universities having set up SFCDM can only gain social benefits without any economic benefits.) However, "the introduction of MOOCs can make up the shortage of funds, classrooms and teaching resources." [7] MOOCs are abundant in resources, most of which are freely delivered by famous teachers. This substantially alleviates the salient problem of limited teachers and funds for SFCDM.

Table 3. Statistical data of educational funds of sample university SFCDMs and paralleled non-SFCDMs (by the end of August 2016) (Unit: RMB).

\begin{tabular}{|c|c|c|c|c|c|}
\hline Chinese universities and colleges & SFCDM name & $\begin{array}{c}\text { Tuition Year } \\
\text { RMB (domestic } \\
\text { learning stage) }\end{array}$ & $\begin{array}{c}\text { Teaching and } \\
\text { personnel } \\
\text { expenditure/each } \\
\text { student/Year } \\
\end{array}$ & $\begin{array}{c}\text { Paralleled Non- } \\
\text { SFCDM } \\
\text { tuition/Year }\end{array}$ & $\begin{array}{c}\text { Teaching and personnel } \\
\text { expenditure of Paralleled } \\
\text { Non-SFCDM/each } \\
\text { student/Year }\end{array}$ \\
\hline $\begin{array}{c}\text { Xi'an Jiaotong-Liverpool } \\
\text { University } \\
\end{array}$ & Architectural Design & 90000 & 63950 & N/A & N/A \\
\hline Wuhan University of Technology & Arts and Design & 46800 & 35569 & 6750 & 4638 \\
\hline $\begin{array}{c}\text { Nanjing University of Science and } \\
\text { Technology }\end{array}$ & Industrial Design & 18000 & 16773 & 6800 & 4825 \\
\hline Anhui Polytechnic University & $\begin{array}{c}\text { Visual } \\
\text { Communication } \\
\text { Design } \\
\end{array}$ & 10000 & 11901 & 7000 & 5143 \\
\hline Hunan City University & $\begin{array}{c}\text { Visual } \\
\text { Communication } \\
\text { Design }\end{array}$ & 27500 & 20912 & 8000 & 5669 \\
\hline $\begin{array}{l}\text { China Australia Business College of } \\
\text { Shanxi }\end{array}$ & $\begin{array}{c}\text { Figure Image } \\
\text { Design }\end{array}$ & 20000 & 8265 & 8800 & 5926 \\
\hline $\begin{array}{c}\text { Zhejiang Fashion Institute of } \\
\text { Technology }\end{array}$ & Costume Design & 15000 & 9387 & 6000 & 4322 \\
\hline
\end{tabular}

\subsection{Close to Real International Studying Environment - A Window to Understand and Adapt to International Learning and} Way of Life

According to investigation, studying and living overseas, either for a short or long period of time, is strange to most SFCDM students. Only a small proportion of these students have gone overseas as short-term travelers. As a matter of fact, SFCDM students will ultimately travel abroad for a long period of time, either studying or working. Currently, many colleges and universities have held various activities such as international study tours, summer camps and other training projects, and frequently invite overseas experts, scholars and international students for academic lecturing, communication and cooperative exhibitions. However, these are barely enough to fundamentally solve the problems that SFCDM students may encounter once they set foot on an alien land. MOOC, as a window for students in SFCDM to understand and adjust to the foreign way of learning and living ahead of time, is a strong supplement. Recommended MOOCs from countries where students are meant to study can teach unique educational concepts and provide special teaching programs of that country. This will give students the opportunity to be immersed in an international studying environment and be encounter the thoughts, living situations, minds and habits of people from every corner of the world. They can also cultivate cross-culture communication ability and an awareness of international cooperation by engaging with the culture, history, economy, politics and customs of different countries, and thus can fully adapt to studying and living overseas. "MOOC combines studying with everyday life, fully playing its own part." [9] 


\subsection{A Helper to Enhance Autonomous Learning Awareness}

"MOOCs, offering courses for professional study, serve to encourage learners to achieve autonomous learning by setting their individual learning objectives." [6] As a learning system established on the basis of autonomous learning which both emphasizes and depends on the awareness of independent learning, MOOCs, to a great extent, help cultivate students' autonomous learning ability by recommending, guiding and encouraging students to utilize learning resources. As we know, self-study and self-improvement ability are extremely essential, especially for SFCDM students since the achievement of innovative and unique design always derives from a designer's own thinking and innovation. Thus, unstoppable passion serves as one of the objectives for cultivating talents in SFCDM, and it also conforms to the international standard for innovative talents in contemporary design. Figure 2, summed up from a questionnaire given to SFCDM students from investigated universities, is a proportional relation graph concerning ways to enhance autonomous learning awareness and ability. It demonstrates that MOOC, in comparison with other media tools, accounts for the highest proportion, higher than APP learning resources at $27.5 \%$. This demonstrates its effectiveness in improving students' autonomous learning ability.

\section{Proportional relationship of ways and means to enhance the autonomous learning awareness and ability}

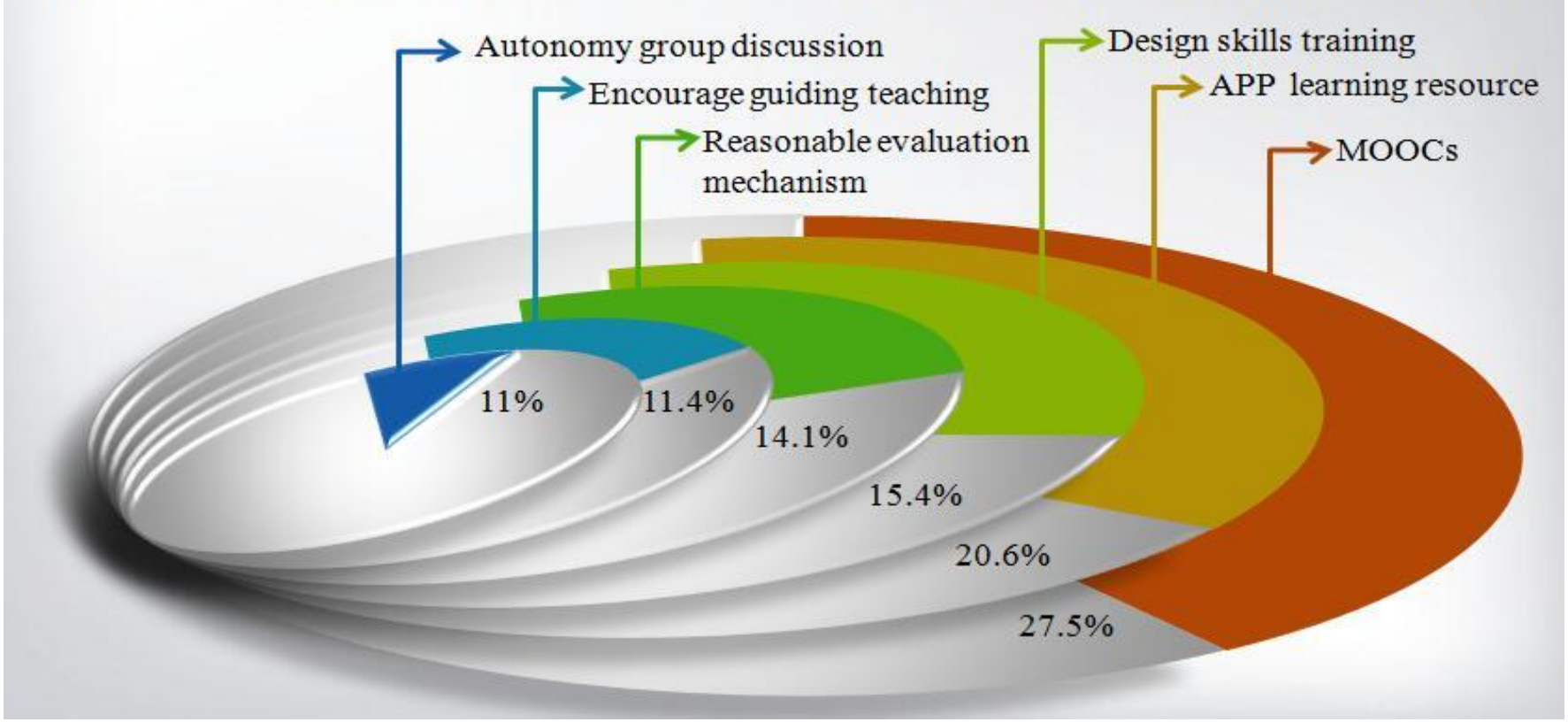

Figure 2. Proportional relation graph of ways and means to enhance the autonomous learning awareness and ability

\subsection{Helping Shape International Vision and Cultivate Design Innovation Ability in a Multicultural Setting}

The ultimate aim of SFCDM projects is to cultivate internationalized, innovative and versatile talents. Therefore, it is of great significance for students to shape an international vision and make designs embodying elements from various cultures. Thanks to the well-rounded, diversified and extensive learning resources available in MOOCs, students are brought into a broader international environment. Even though it is just an online virtual environment, some fundamental characteristics of MOOCs, such as its systematic teaching, resource sharing and non-utilitarianism, determine that participants can concretely know, learn and experience what international education or even international community is. This is beneficial to students' shape and expansion of international vision. In addition, students engaged in MOOCs can communicate and consult with students and teachers worldwide. It is reported by Coursera that "an average of 33,000 students are involved in each MOOC course on its platform." [5] Having the opportunity to exchange both Chinese and foreign views on art culture and design thoughts on the same platform, participants will be provided with a broad space for contemplation, and thus they can generate inspirations in arts and design. Even in courses related to science, engineering and nature science, diversified cultures and knowledge will still exert a strong impact on students. Therefore, it is undoubtable that MOOCs serve as the driving force for student's cultivation of design innovation quality among diverse cultures. Figure 3 is summarized from a questionnaire answered by investigated students, demonstrating a variety of design innovation qualities which have been practiced and improved due to MOOCs' involvement. 


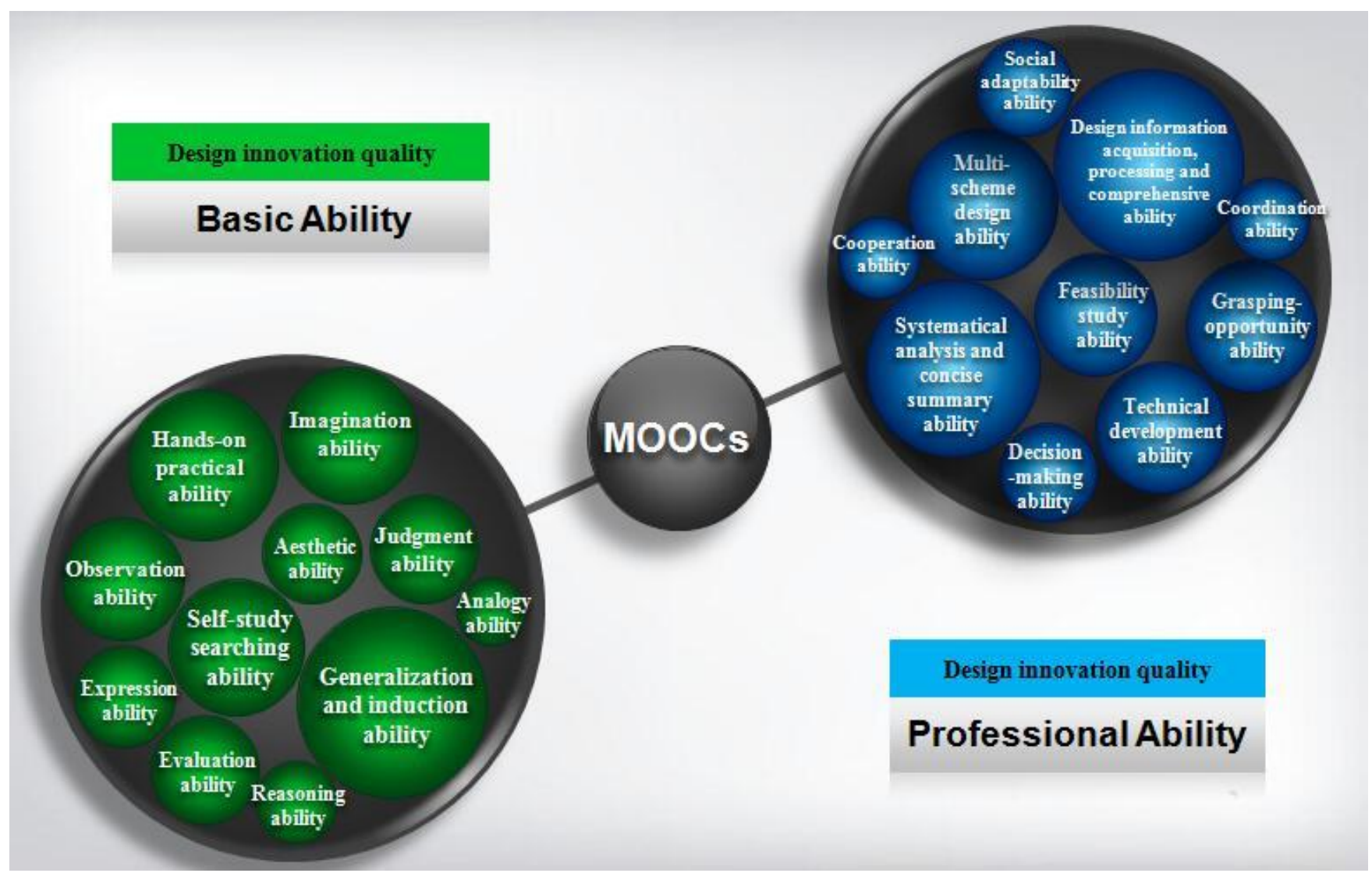

Figure 3. The cultivation of students' design innovation quality under the action of MOOCs

\subsection{An Assistant to Improve Teaching Ability and Level}

MOOCs help to promote students' autonomous learning, independent thinking and the acquisition of diverse knowledge and skills. In other words, preceding the start of some courses, students are likely to have a higher level of comprehensive quality, learning ability as well as knowledge storage. MOOCs require that "teachers are supposed to have a profound understanding of the curriculum system for university students and correspondingly adjust curriculum's knowledge structure and contents." [2] It is undoubtable that teachers are brought under great pressure. Accordingly, the introduction of MOOCs mechanism is bound to give teachers in SFCDM projects the incentive to reflect upon current teaching situations and their own teaching skills. In this way, they will take the initiative to improve and integrate teaching contents deeply and explore ways to make a breakthrough in teaching approaches. Meanwhile, by allowing teachers to be aware of their transition from simply giving lectures to inspiring and mentoring students, this mechanism can genuinely improve their teaching ability and level as well as their understanding of what is being taught. All these above, if achieved, will enhance the comprehensive quality and ability of both teachers and students while spurring on the effective operation of SFCDM. In addition, MOOCs also stimulate the reform of educational management concepts and teaching modes among colleges and universities.

\subsection{Paying Attention to Balance}

Firstly, the differences in students' learning levels and progress can be well balanced. Resources in MOOCs can be utilized by students to make up for their own weaknesses while bringing out their strengths, which aids teachers' targeted teaching, particularly their moderate control of how to explain difficult and important contents in both English teaching and major teaching. Secondly, some students coming from families with harsh economic conditions can employ MOOCs as a balance and supplement for lack of learning resources. They can be freely accessible to many learning resources for both English learning and major study. This will help them achieve better grades which can guarantee them a greater possibility of winning scholarships and student grants both at home and abroad, and they will hopefully also have the opportunity to study abroad and obtain a degree. 


\section{Drawbacks analysis and availability optimization}

\subsection{High but Prevailing Drop-out Rates in MOOCs}

In the application of MOOCs, higher drop-out rates are a long-existing problem, and they were observed without exception in the seven investigated Chinese colleges and universities. As is shown in Table 4, for students studying in colleges and universities with different educational levels, their drop-out rates in MOOCs do not vary significantly. Even in top-ranking colleges and universities whose enrollment scores are much higher, students' high drop-out rates are still unavoidable. Therefore, it can be concluded that students' grades, either high or low, are not the determinant when it comes to the occurrence of drop-outs from SFCDM in MOOCs. Through a random interview with students, reasons why they decided to drop out can be concluded as follows: firstly, design courses in MOOCs have intrinsic problems. For instance, although much importance is attached to theoretical knowledge and case analysis, weak design interactivity is inevitably manifested because students' needs for practical training and application are not satisfied. Secondly, in spite of strong time flexibility in MOOCs, students' study time is still not guaranteed due to their full arrangement in spare time, such as participation in social activities, internship as well as part-time jobs. Thirdly, the assessment mechanism of MOOCs and requirements from universities on obeying such an assessment mechanism are not strict and mandatory enough. As a result, dropping out will cost nothing for students. Fourthly, SFCDM students, compared with their counterparts from non-SFCDM, have more opportunities to be accessible to foreign teaching concepts and methods, qualified teachers and foreign environments. Thereby, their loss of interest during learning process triggers their decision to drop out.

Table 4. Elected MOOCs number and drop-out rate situation of samples（by the end of August 2016）

\begin{tabular}{|c|c|c|c|c|c|}
\hline Chinese university & Cooperative major & $\begin{array}{l}\text { Actual Students number } \\
\text { in Chinese campus }\end{array}$ & $\begin{array}{c}\text { Elected } \\
\text { MOOCs } \\
\text { number/Year }\end{array}$ & $\begin{array}{c}\text { Uncompleted } \\
\text { MOOCs } \\
\text { number/Year }\end{array}$ & $\begin{array}{l}\text { Drop-out } \\
\text { rate/\% }\end{array}$ \\
\hline $\begin{array}{c}\text { Xi'an Jiaotong-Liverpool } \\
\text { University } \\
\end{array}$ & Architectural Design & 32 & 227 & 102 & 44.93 \\
\hline Wuhan University of Technology & Arts and Design & 391 & 1681 & 811 & 48.25 \\
\hline $\begin{array}{c}\text { Nanjing University of Science and } \\
\text { Technology }\end{array}$ & Industrial Design & 89 & 329 & 173 & 52.58 \\
\hline Anhui Polytechnic University & Visual Communication Design & 74 & 481 & 303 & 62.99 \\
\hline Hunan City University & Visual Communication Design & 92 & 323 & 197 & 60.99 \\
\hline $\begin{array}{l}\text { China Australia Business College of } \\
\text { Shanxi }\end{array}$ & Figure Image Design & 57 & 199 & 143 & 71.86 \\
\hline $\begin{array}{c}\text { Zhejiang Fashion Institute of } \\
\text { Technology }\end{array}$ & Costume Design & 165 & 511 & 357 & 69.86 \\
\hline
\end{tabular}

\subsection{The Occurrence of Over-dependence}

According to some questionnaires submitted by students, with the gradual improvement of their learning ability and knowledge level as well as more familiar use of MOOCs, a small number of students have stronger capability to comprehend and master MOOCs than before. As a result, their interest in selecting courses and confidence are correspondingly improved. In addition, due to the fact that MOOCs are boundless in space and time, abundant and outstanding in learning resources, innovative in teaching process and have a comfortable and convenient personalized learning environment, these students are greatly attracted and thus become over-dependent. What's worse, students lacking in self-control may become overly obsessed with virtual networks like MOOCs. Gradually, these students mentioned above are prone to lose interest in traditional classroom teaching and routine curriculums and even, in the worst cases, ignore them.

\subsection{Undue Choice or Adverse Effect Caused by Inadaptability}

Although the study demonstrates that MOOCs contribute to the enhancement of students' independence, initiative and confidence, there are still some exceptions. For example, some students may make wrong choices repeatedly about the courses to be selected due primarily to an unawareness of their depth and difficulty level. Courses beyond students' expectations in terms of difficulty and content will not only give rise to higher drop-out rates, but also be detrimental to 
students' learning initiative and confidence. This will impede students' motivation to continue learning and ultimately things may backfire. Worse still, due to the overall weak English language proficiency of SFCDM students, the majority of them, at the initial stage, reflect that they have difficulty adapting to English courses in MOOCs during their learning process. If necessary mentoring mechanisms in the following-up phase are not offered, it is impossible to create a relaxing environment suitable for learning English. Consequently, the ever-increasing learning pressure and the slow or even stagnant learning progress are bound to undermine the learning objectives set by students and further provoke their fear of learning English.

\subsection{Lack of Courses for Practical Training and Immediate Interaction}

It is generally reflected by students that MOOCs are lacking in practice courses for design majors, especially those for professional practical training. At the current stage, MOOCs can rarely offer courses which can be directly connected to social practice and design practice by simulating practical training. "MOOC's failure to provide a study mode favorable for continuous participation in social practice is regarded as one of the major barriers to its potential for bringing about profound changes." [12] Another disadvantage of MOOCs is the lack of sessions for real-time synchronous communication and immediate interaction. While online courses are delivered through asynchronous teaching which can bring convenience free from barriers caused by separation in space and time, the loss of favorable immediate exchanges and communication is at the same time inevitable. Instead, through vivid, earnest and direct immediate communication with overseas teachers and students, students in SFCDM can not only participate in international classes in person, but also have a chance to demonstrate their English language proficiency. Meanwhile, immediate discussion is more conducive to the exchange of innovative ideas and the burst of design inspiration.

In order to achieve such an approach, social forces need to be mobilized to build an elaborate practice platform in MOOCs for design majors. Colleges and universities need to utilize extensive alumni resources and resources brought from international, school-local government as well as school-enterprise cooperation. By cooperating with top designers, projects managers and relevant industries, they should be committed to developing both online and offline courses in which students are led to participate in and investigate practical projects or design for exhibition or related competitions through network technologies (such as live video playing or on-the-spot explanation). Universities need to introduce related incentive and innovative policies and make timely adjustments. They must also encourage teachers to open real-time online courses or promote their application of cutting-edge artificial intelligence technology, which is likely to be the trend of MOOCs future development.

\subsection{Students' Boredom after Repeated Participation Caused by the Standardization and Linearization of MOOCs}

MOOC simply targets online groups and its own teaching system is not yet sufficiently developed. Despite the fact that MOOCs add some innovative practices such as brainstorming, interesting quizzes and peer assessment, programmed teaching and structured knowledge analysis still dominate the overall teaching process. Therefore, in spite of some changes, this whole process seems to follow the old routine of traditional classroom teaching in its organization form. Figure 4 illustrates the standardization and linearization processes of MOOCs and the circular function diagram of MOOCs and offline learning environment. "MOOCs are generally managed by a centralized platform where video playing, discussion board, standard test for practice and course readings and files are provided. Courses are still teacher-centered and stick to the linear model of weekly-based learning." [11] MOOCs fail to make a non-linear differentiation and adjustment on the basis of various learning experience, comprehension and feedback from assorted groups, which is unfavorable to the acquisition of individuality, flexibility and comprehension for SFCDM students.

\subsection{Unfavorable for Teachers and Teaching Management}

MOOCs indeed play an essential role in building curriculum for SFCDMs and deepening teaching. However, studies show that the MOOCs mechanism brings teachers pressure, an invisible pressure that promotes their self-improvement but also has a negative impact on the psychology of those who easily feel anxious, such as by reducing their teaching confidence and triggering their anxiety. In addition, as MOOC is simply incorporated as an auxiliary teaching system by many majors, students' learning process in MOOCs is free from teachers' management. Therefore, teachers can only know their learning process through indirect ways. Under this circumstance, both students' practical learning condition in MOOCs and their immediate feedback are unable to be reflected synchronously. This leads to the overlapping of content between classroom learning and MOOCs online courses, resulting in the misplacement of targeted mentoring. Therefore, an effective solution 


\section{MOOCs linear workflow}

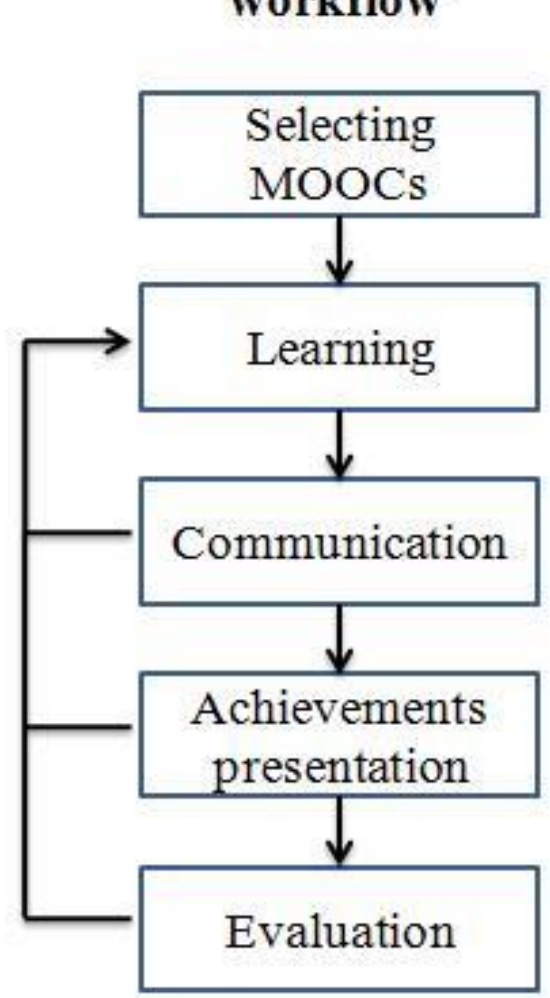

\section{Online learning environment}

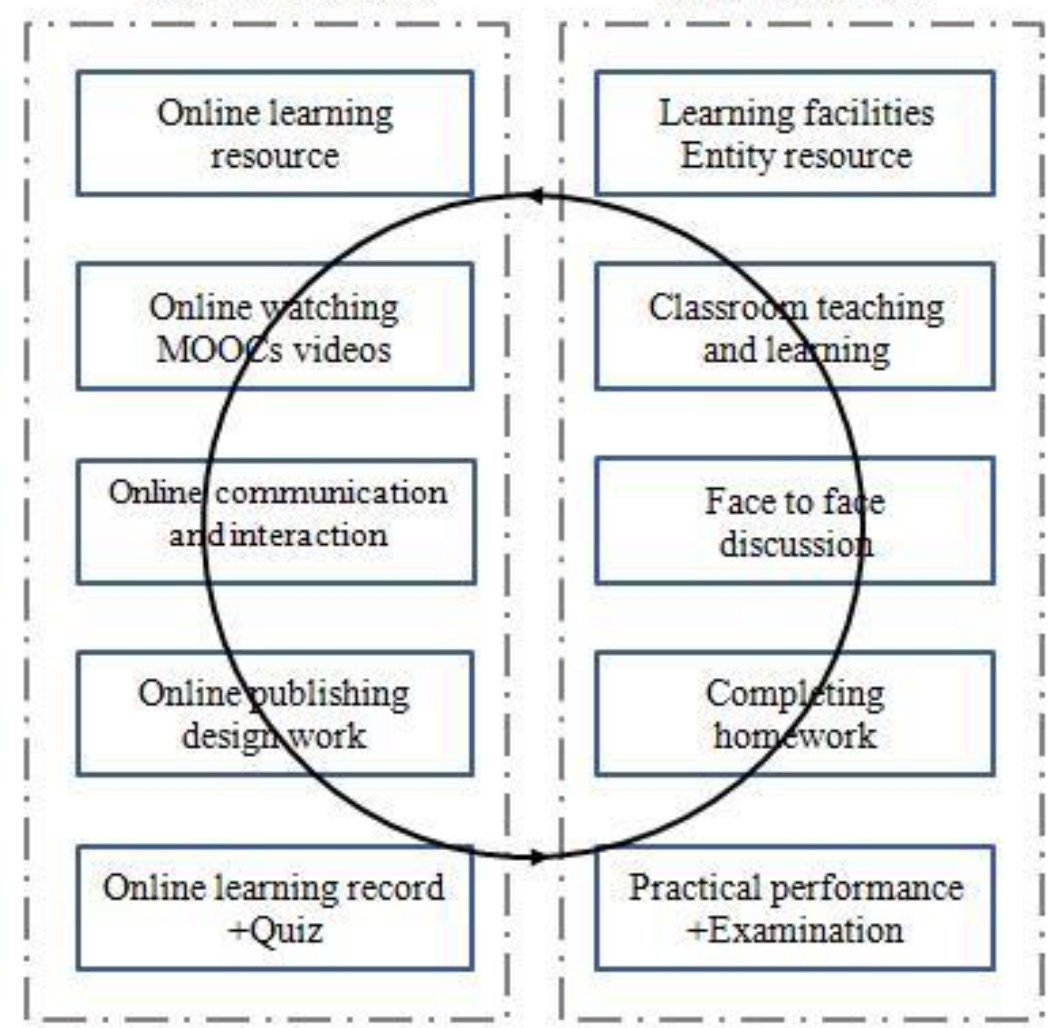

Offline learning environment

Figure 4. The standardization and linearization processes of MOOCs and the circular function diagram of MOOCs and offline learning environment to such problems is to explore ways to build a communication channel among teachers, between teachers and students, and among students in the introduction of the MOOCs mechanism so that the immediate sharing of teachers' teaching skills and students' learning processes can be both achieved in the age of MOOCs.

\section{Conclusions}

Based on a sample survey among multiple regions through various approaches, it can be concluded that the advantages of the intervention impact of MOOCs teaching mode on SFCDM outweigh its disadvantages. From the perspective of students, this teaching mode contributes greatly to their autonomous learning, adaptability to foreign educational concepts and methods, international vision and thinking, and design innovation ability. With regard to teachers, it is conducive to elevating their ability in teaching and their control over the whole class and strengthening their exchange and communication with students. It also benefits teachers' achievement of both an overall balance of and a targeted emphasis on important and difficult contents as well as teaching schedule during their teaching progress. Furthermore, MOOCs teaching mode exerts a positive impact on improving teaching management mechanisms and promoting the reform of the Chinese teaching system, especially by facilitating teaching innovation in SFCDM.

Meanwhile, several common disadvantages of MOOCs analyzed from our survey should not be ignored. To avoid or lessen their negative impact, effective measures based on specific majors and students should be made in order to match the construction of MOOC's complementary practice platform for design majors: a regular appointment mentoring mechanism in which teacher participate in students' learning process in MOOCs and a MOOCs tracking system for reminding and supervision together with evaluation mechanism. In this way, the errors appearing in the application of MOOCs can be effectively corrected so that a mature and sound SFCDMs MOOCs teaching mode will be shaped to effectually improve the learning efficiency and the cultivation quality of SFCDM students. In this sense, educational concepts and teaching modes of MOOCs can be extensively applied and fully implemented in Chinese colleges and universities. 


\section{Acknowledgements}

This research is supported by Anhui Province key education and teaching projects of universities and colleges "School running characteristics exploration and innovation of international engineer institute of Anhui Polytechnic University" (2016jyxm0091);2017 National Social Science Fund pre-research Project of Anhui Polytechnic University "Collaborative innovation assimilation and alienation research of intangible cultural heritage protection of the Yangtze River Delta" (2017yyrw01); Anhui provincial philosophy and social science planning project "Research on the internationalization strategy of higher education in Anhui Province"(AHSKY2016D29); "International compound students training mode of Local colleges and universities in global MOOCs era" (2014jyxm43).

\section{References}

1. W. Abeera and B. Miria, "Students' Preferences and Views About Learning in a MOOC Procedia", Social and Behavioral Sciences, Vol 15, no2, pp. 318-323, March 2014.

2. H.Z. Deng, M.J. Li, Y. Chi and S.Y. Tan, "The Construction of Course Knowledge System in the Period of 'MOOCs', Course education research, pp. 5-7, July 2013.

3. A. Fox, "From MOOCs to SPOCs", Communcation, Vol 56, no 12, pp.38-40, December, 2016.

4. S. Karnouskos, "Massive Open Online Courses (MOOCs) as an Enabler for Competent Employees and Innovation in Industry", Computers in Industry, Vol 17, no 6, pp. 1-10, June 2017.

5. S. Kolowich, "Coursera Takes a Nuanced View of MOOC Dropout Rates", Chronicle of Higher Education, April 2013.

6. C. Milligan and A. Littlejohn, "Supporting Professional Learning in a Massive Open Online Course", The International review of research in open and distributed learning, Vol 15 , no 5, pp.197-213, November 2014.

7. L. Li," The New Idea of the Development of Confucius College -- the Application of the Teaching Mode of the MOOCs", Journal of Southwest University for Nationalities, pp. 224-229, December 2014.

8. W. Li, Q. N. Xiong and Y.H. Cai, "On Education Sovereignty of Higher Education Internationalization in the MOOC Conditions", Higher education research, pp. 22-26, February 2015.

9. F. Li and M.D. Huang, "The Opportunity and Challenge of 'MOOCs' to the University", China higher education, pp. 22-26, July 2014.

10. J.H. Lin and M.J. Liu, "On the Quality Construction of Chinese-foreign Cooperation in School Running", Education research, pp. 72-78, October 2013.

11. G. Sadykova, "Mediating Knowledge Through Peer-to-Peer Interaction in a Multicultural Online Learning Environment: A Case Study of International Students in the US", The International review of research in open and distance learning, Vol 15, no 3, pp.24-49, July 2014.

12. D. Savino, "The Impact of MOOCs on Human Resource Training and Development", Higher Education Theory Practice , Vol 16, no 3, pp.59-64, March, 2016.

13. N. Sonwalkar, "The First Adaptive MOOC: A Case Study on Pedagogy Framework and Scalable Cloud Architecture-Part I", MOOCs Forum, DOI: 10.1089/mooc. pp. 22-29, July 2013.

14. J.K. Stine, "MOOCs and Executive Education", Unicorn, Vol 13, no 6, pp.65-75, June 2017.

15. L.Wilson and A. Gruzd, "MOOCs-International Information and Education Phenomenon", Bulletin of the Association for Information Science and Technology, Vol 40, no5, pp.35-40, June/July 2014.

16. D.Y. Yang, D. Adamson, C.P. Rose and T. Sinha, “'Turn on, Tune in, Drop out' : Anticipating student dropouts in Massive Open Online Courses", Proceedings of the 2013 NIPS Data-Driven Education Workshop, November 2014.

Tiejun Zhu graduated from the School of Arts, Anhui Polytechnic University, for the degree of Master. His research interests include graphic design and design education. He worked in Phuket Campus, Songkhla Prince University in Thailand as a guest teacher from 2004 to 2005. He visited University of Liverpool in the U.K. as a visiting scholar sponsored by China Education Ministry from 2014 to 2015. Now he is an associate professor of the School of Arts, Anhui Polytechnic University, Anhui, China. He is vice Chief-secretary of Anhui Ceramic Association.

Michael Berry graduated from University of Liverpool, for the degree of Master. Now he is a lecturer of English Language Centre, University of Liverpool, Liverpool, United Kingdom. 